\title{
Specialized Teaching Proof against the "Déjà-La" Case Study of Two Teachers of Adapted Physical Activity in Tunisia
}

\author{
Lengliz Hanene1, Guerchi Meher ${ }^{2}$, Carnus Marie France ${ }^{3}$ \\ ${ }^{1}$ EFTS-Laboratory of Education, Formation and Knowledge, UMR University of Toulouse, France/Higher School \\ of Sport and Physical Education, Ksar-Said, Tunis \\ ${ }^{2}$ EFTS-Laboratory of Education, Formation and Knowledge, UMR University of Toulouse, France/Higher School \\ of Sports and Physical Education, Kef, Tunis \\ ${ }^{3}$ UMR EFTS, University of Toulouse 2-Le Mirail, France \\ Email:makwiss@yahoo.fr
}

Received 4 March 2015; accepted 27 November 2015; published 30 November 2015

Copyright (C) 2015 by authors and Scientific Research Publishing Inc.

This work is licensed under the Creative Commons Attribution International License (CC BY).

http://creativecommons.org/licenses/by/4.0/

(c) (i) Open Access

\section{Abstract}

This article is a part of a research which joins in a work of a doctoral thesis in clinical didactics of physical education (PE). We analyze the Specialized Teaching Practices (STP) intended for pupils with particular needs, presenting here a mental deficiency, by trying to articulate certain concepts stemming from disciplinary didactics together with a clinical study of psycho-analytical orientation. In view of our progress, which is still at an exploration stage, our interest is focused on the concept of "déjà-là", representing the hidden side of the Teacher's Decisional Process (TDP) and providing motives and potential drives of the teacher's professional activity. We proceed to the study of closely-related cases of two teachers of Adapted Physical Activities (APA) practiced in Specialized Institutions in Tunisia. The analysis of the contents of the interviews organized according to the clinical didactic methodology shows that the teacher's "déjà-là" can determine to a great extent his didactic and professional decisions.

\section{Keywords}

Specialized Teaching Practice, Adapted Physical Activities, Clinical Didactics, Case Study, "Déjà-Là", Mental Deficiency, Teacher's Decisional Process, Disciplinary Didactics

\section{Introductory Developments}

Our interest is directed in this article at the specialized teaching practices stemming from this evolution which seems to take shape these last years in the utilization of adapted physical and corporal activities (APA) acting as 
a trigger to allow the intellectually deficient individuals to benefit from "an educative and integrative institutional project which allows them to become consumers of sportive practices, a statute which until these previous years has been denied to them” (Brunet, Biu-Xuan, \& Bluteau, 2001: p. 135). This new orientation should allow these handicapped people to invest in significant practices corresponding to their physiological, psychological and social needs.

Nevertheless, the interest shown to the APA and their utilization in an educative and integrative project raises a question, on one hand, on the crucial and major importance of a deep reflection on the teaching content in order to adapt it to the specific needs and characteristics of people with deficiencies and, on the other hand, on the importance of the work of a specialized teacher who has received an additional training thus allowing him to be more aware to the monitoring and transmission of adapted knowledge.

Besides, our positioning in scientific research, which is implemented in the crossroad of didactic and psychoanalytic clinical orientation, leads us to ponder upon the teaching practice, here, specialized, first as a teaching process based on the articulation of three distinct and interdependent principles of the didactic system ${ }^{1}$ : the principle of the specialized teacher who has intentions and who takes decisions in the contingency of the didactic situation; the principle of the student, here intellectually deficient, who has particularities and needs allowing him to actively build up his knowledge and finally the principle of the contents taught or of the discipline taught which cannot avoid a restructuration and a didactic transposition allowing the learner to access to an adapted knowledge.

In second position, the teaching activity in relation to the clinical one is considered as an activity which essentially binds the learner "in its both psychic and social dynamics" (Beillerot, Blanchard-Laville, \& Mosconi, 1996). This approach "integrates the subject's dimension" (Carnus, 2003), who is a subjected individual, particular and divided, "taken in the didactics" (Carnus, 2013) and who undergoes external influences related to the context and to the institutions in which he works on one hand, and the internal self-influences due to a constitutive history of his personal and professional epistemology on the other hand (Carnus, 2003). Therefore, studying the specialized teaching practices implies perceiving the psychic reality of the observed professional situation which is a reality partly unconscious and partly conscious. It is made of "desires, phantasms but also affections, emotions as well as perceptions and representations of internal objects" (Ciccone, 2012: p. 75). The teaching practices look like a very pertinent topic of research and they can be qualified as "productions by integrating other dimensions of the knowledge scope and affects for instance. These practices are pursued through behavioral aspects, but also through personal, inter-subjective, institutional, ideological processes to which they are related in an active way” (Bru, 1992).

\subsection{The Issue}

Through this project of research in the framework of a thesis in the process, our wish is to bring another vision and understanding of the complexity of the teaching-learning process which is elaborated between external and internal determinations and which develops in a space between constraints and freedom that the teacher builds up partly unknowingly. We are centered more particularly on the nature of the challenges of knowledge which are transmitted between specialized teachers in Tunisia, by adopting an idea according to which the phenomena related to the transmission-acquisition of knowledge in PE seem to belong to a conscious and unconscious psychic dynamics which determines the practices and places the teaching subjects at the heart of analyses for another outlook and another understanding of the didactic functioning marked by the contingency of all learning (Terrisse \& Carnus, 2009: p. 69). Thus, we start from the decisional "déjà-là" (Carnus, 2003) of the two associated teachers so as to detect and locate the influence of their personal teaching experience, their intentions and their conceptions on practice in the context of specialized teaching.

\subsection{The Deja-La}

\subsubsection{The Conceptuel "Déjà-Là"}

In the didactic field, the notion of conception is defined by Giordan et De Vecchi (1987) ${ }^{2}$ as an element making

\footnotetext{
${ }^{1}$ The didactic system takes into consideration the relationships which exist between the three poles: teacher, knowledge, learner (the threeside didactics) and raises the issue, among other things, of the specificity of disciplinary contents in view of their conditions of transmission and appropriation. The relationship between these three poles makes up the conceptual "backbone" for the transmission of knowledge in a PE classroom (Terrisse, 2001).

${ }^{2}$ Giordan, A. et De Vecchi, G. (1987) Les origines du savoir. Neuchâtel: Delachaux et Niestlé (Garnier et Sauvé, 1999).
} 
part in the building of a knowledge and even allowing for the necessary transformations. For these writers, the conceptions are built on and linked to knowledge. They are elaborated in relation to a given object, by analyzing and synthesizing various types of information. The conceptions refer to a set of ideas that the learner utilizes in order to reason in front of problematic situations. This set of ideas corresponds to an underlying mental structure, responsible for contextual events (Giordan \& De Vecchi, 1997). Thus, the conceptual "déjà-là" allows to give a meaning to the inherent components of practice.

\subsubsection{The Intentional "Déjà-Là"}

The cognitive centre of action refers to a more or less explicit and conscious set of intentions. Intention is a notion borrowed from psychology in the field of researches in didactics where it assumes an undeniable character as a "founder of didactics" (Brousseau, 1998). It is considered as a tension towards a goal and a definitive direction towards an object. According to Bruner (1987) "There is intention when there is orientation and perseverance”. Besides, the project refers to the character of anticipating the action by intentions. It implies a complex frame of intentions which are transformed by interaction into "private intentions" (Carnus, 2009) giving an account of the knowledge to be taught.

However, in order to understand the decisions of a teacher in a didactic interactive situation, we use the notion of intention as this entity is in direct relation such decisions. Indeed, the teacher gets into the classroom carrying a series of objectives set in advance. These objectives undergo noticeable transformations through interaction. For the teacher, the intention is not limited to knowledge only but it is rather extended into other dimensions. We think that the intentions of a teacher are governed by the contingency of a teaching/learning situation, where we witness a genesis of intentions caused by the sequence and the organization of chrono-genetic decisions of the learning situation. This genesis, which indicates the order in which the action of transmitting the taught knowledge should take place, involves a series of social intentions at an early stage. These intentions are later transformed into more personal intentions which represent a prefiguration of the internal didactic transposition. Within the same framework of ideas, Carnus states that prior to the decisions, the more or less conscious intention form an element of the hidden side of the "decisional process" which refers to the causes and motivations and which partly determine the teacher's choice before, during and after the action (Carnus, 2009). Within the "layers of intentions and intentionality" (Portugais, 1998) which act as "filters of didactic action", intention directs the teacher's choice towards a very precise teaching content as well as the way of its transmission in a didactic situation.

\subsubsection{The Experiential "Déjà-Là"}

The experiential centre of action corresponds to the teacher's usual practices (Carnus, 2002) and it refers to everything related to his/her professional experience. Besides, experience is tightly related to the number of years spent in teaching and it refers to a professional path which can be translated into the number of years in teaching. It is made of repeated professional teaching in formal and informal school environment. According to (Carnus \& Terrisse, 2013), experience is enlarged by the variety and the wide range of teaching contexts as well the events which are lived by the subject and which have left their impact in his/her life. The "experiential Déjà-Là" is the explication of experimental knowledge by the teacher which is made from issues affecting the profession. Moreover, the interpretive approach by the researcher has a twofold function: the function of understanding in the sense of "giving reason" to the logic of actors (Bourdieu, 1993) and the function of explaining in the sense of "placing into perspective these logics, even unveil the process on which this dynamics is founded" (Dubet, 1994)

Therefore, to sum up and better locate the various "déjà-là" on the clinical side, we refer to the psychoanalytic theory of Freud's first topic, in order to say that the two "intentional déjà-là" would be located in the sphere of the Conscious. In fact, it is about objectives clearly expressed in the teachers' speeches, while the "conceptual déjà-là" would be located in the Preconscious. This register of the preconscious refers to a pre-thought when we work on the explanation of the action (Vermersch 1994). The "experiential déjà-là" would be well anchored in the "Unconscious" concerning the practitioner's experience. When it comes to explaining teaching practices, this topic reveals the tight link between the three instances of the "id", the "self" and the "superego" These "déjà-là" act, therefore, as personal filters which influence and direct the choice of knowledge to be taught, labeled as "didactic intentions" as well as "the didactic decisions" taken during the teaching session. 


\subsection{Methodological Framework}

We call into mind that, within the framework of this article, we make reference to a didactic clinical approach which makes use of the studies of cases and of various research methods in order to analyze the Adapted Teaching Practices. Thus, we utilize a corpus made of interviews and the filming of PE lessons in the specialized institutions with mentally-handicapped students. This device of data collecting is marked by its temporal mode presented in three time sequences (the déjà-là, the test and the after test).

Compared to our stage of progress in the thesis work, we are interested in the first time sequence (the déjà-là) of the methodology which allows to highlight both personal and social dimensions (Haber, 2012) through the filters of teaching (Loizon, 2004). This “decisional déjà-là" stems from the influence of several "déjà-là”: the "experiential déjà-là” ${ }^{3}$ which refers to the particular experience and history of the teaching subject, the conceptual déjà-là which refers to the conceptions that the figures out from the activity which he is going to teach and which allows him to give a meaning to the constitutive elements of the practice and finally the "intentional déjà-là" which refers to the teacher's educative and didactic intentions. These three "déjà-là", a hidden of the decisional process, represent three major instances ahead of any decision making (Carnus, 2003) by providing motives and reasons of all professional activities. For this purpose, we have performed some semi-directed interviews made of questions which are related to the associated teaching subjects. We have asked questions related to the conceptions of mental handicap and the adapted physical activity (APA), other questions are related to the intentions of teaching adapted gymnastics, our chosen support activity, and finally questions related to the experience of two teachers working in two different specialized institutions in Tunisia as well as their own experience in relation to the teaching of adapted physical activities (APA) in general. These interviews allow us, after quantitative analysis of the content as it is conceived by Bardin (1977) to extract the traces of constitutive elements of the decisional déjà-là of the two associated specialized teachers who volunteered to participate to our research (Médi and Manel). It is an effort of interpretation from a corpus of verbatim which fluctuates between two poles: on one hand the rigor of objectivity and on the other hand the fertility of subjectivity (Bardin, 1977). Indeed, the content analysis is organized around several chronological phases: a pre-analysis, material exploitation, results processing, inference and interpretation.

The treatment of interviews lies first on the floating reading transcript of the "déjà-là" which allows us to extract the salient elements of the case. The second time of the analysis consists in locating in a more systematic way certain extracts, units of meaning or occurrences of a conceptual, intentional or experiential nature echoing our research concerns. Thus, the decisional déjà-là is a reconstruction elaborated by the researcher owing to the crossing of different data collected upstream and sometimes downstream of the observation in situ. "Between the rationality of the approach and the subjectivity of the researcher, the buildup of the case in clinical didactics proceeds in countdown to go to the interpretative statements pointing at the possible causalities, here linked to the decisional déjà-là. Like any product of the clinical elaboration, these statements always remains a point of view which in the third and last time of the research, the "après-coup" is confronted to the point of view of the observed subjects (Carnus, 2014)

\subsection{Main Results}

After an analysis of the Corpus of the Verbatim according to the technique of analysis content which allows to build up the case (Bardin, 1977; Mucchielli, 1975) we proceed to the presentation of clinical didactic stickers organized according to the three "déjà-là" categories for the two volunteering teachers and collaborators that we called Medi and Manel.

\section{The Case of Medi}

\subsection{Experiential Déjà-Là}

Medi is a specialized teacher in APA. He has 9 years of experience in this branch. He states that he did not really opt for this branch of education (APA) as a training path. This field was a new option at the High Sports In-

\footnotetext{
${ }^{3}$ The experience is made of the repeated professional practice of the teacher in school environment or outside the school. According to (Carnus \& Terrisse, 2013), it is enriched by the variety and the multiplicity of teaching contexts as well as of the event experienced by the subject and which had an impact on him. The experiential déjà-là is the specification of knowledge-experience by the teacher formed from the questions touching the exercise of the profession.
} 
stitute of Physical Education in Tunisia. Medi points out that he “...heard about a new branch...” and he adds that his choice was mainly a choice triggered and boosted by the fact that this field of studies will guarantee his career: "Honestly, we were assured the immediate access after training to the job market, it was wonderful for me, and I said to myself that ultimately it is a choice which will nevertheless guarantee my professional future". Medi adds: "I don't regret my choice; I feel comfortable where I am".

1) Medi, between theory and practice

Medi deems that he has received insufficient academic training which is far from reality. He thinks that the fact of receiving theoretical strategies of teaching, scientific knowledge and a physical education has a major importance: "it is the basis; it is a platform of our work". However, in the very particular context of the handicap, one must really point out the importance of practice and experience. In this respect, Medi underlines that "the specialized teacher must acquire the skills from the field by necessity, and besides, we cannot succeed in this field with previously prepared strategies and ready-made recipes”. This speech supports Rouzel's idea (Rouzel, 2004: p. 95) according to which the theories acquired at the university are sort of "bush, rather dense, which hides the forest of practice whose heart, its relationship and the encounter of another human being, make up a real living enigma”. In front of this observation, Medi recommends a reform for specialized educators: “A real know-how must be supported by practice”.

2) Medi, from Hardship to pleasure

The years of experience spent at the centre of the mentally handicapped allowed Medi to change his attitude towards the latter, an attitude which started with much hesitation and suffering: "Each session was for me a burden, a mountain behind which I could see nothing”, he declared to us. This attitude seems to be transformed in a mixed feeling of love, growth and recognition. His speech confirms this opinion: "I love my students; you can believe me. They mean a lot in my life". Strengthened by his experience, Medi is less worried of the content of his sessions which, with much reflection and research, become a source of joy, growth and confidence. He explains to us his worries in this way: "I have took hold of courage in my hands, I have tried to understand my students, to get nearer to them, understand their problems and needs, and there I started to grow up by discovering from one training session to another, the performances and the unexpected feats of my students. Really it makes me feel happy." Thus for Medi, "Intelligence, commitment and challenge are attitudes that must be acquired by the teacher in order to succeed in his career".

Besides, the years of practice with the mentally handicapped students have allowed him to make very strong relationships and affects which allowed him to develop his professional character: "I am king in my position" he states. He has becomes more self-confident. His vision of life has changed. These words are confirmed in his speech: “The years I spent with my students have changed my lifestyle”. Thus, Medi gains personal and professional confidence. he has built up and he continues his "professional game" which is according to Aulagnier (1975), made up of a history represented by the set of identifying statements which he keeps in his memory and which manifest themselves in his current life and in his relationship with an identifying project.

\subsection{The Conceptual Déjà-Là}

1) From Denial to Challenge

In his speech, Medi seems to completely deny the existence of the handicap. For him, the term "handicap" has a bad impact on the person classified as such. This is the same for the dominating representations of the handicapped person in society. He points out that "the term 'handicapped' is an aggression, a limited judgment which, in its turn, limits the misjudged person". In the same order of ideas, it refers to the fact that it is a human being able to think, who has needs, ambitions, dreams, just like anybody else. Medi thinks that it is just a representation, unclear in people's mind as they have neither the chance nor the opportunity to live with the handicapped. And to be more precise about his conception, he uses the metaphor of the rich man and the poor man by saying: "It's like the representation of the rich man and the poor man. Is the poor man deprived money a handicapped person? Certainly not. And the rich man, who can get everything with his money, is he able to do everything? Also certainly not. Here you are!”

Then it seems that Medi's conception of "handicap” is tightly linked to an intimate personal and experiential rapport in consideration to the daily and regular relationship and contact with the mentally handicapped at the precincts of the centre. He adds in this context: "I cannot give you a meaning of the word 'handicap', maybe because I see them more closely and therefore I know more closely what a handicap means”. This personal 
conception of handicap can allow us to understand the rapport that Medi undertakes with his students. What drew my attention was that Medi tries to transmit this form of handicap-denial to his students. Indeed, he told us to ask this question: "What does the word 'handicap' mean to you?" to his students who will now reply: "the handicapped person-it's the jobless, the thief, and the unable one”. This relationship of complementarily between the teacher and his students is at the origin of a very positive atmosphere in the classroom. Besides, Medi confirms this by saying: "The handicap is a challenge". This particular conception of the handicap is built in a particular space which, according to Freud, shows a lot of inventions. It is in this framework that, for a subject, a rapport to the world, to others and to himself is going to be restructured (Freud, 1927).

2) Teaching APAs means to be "an artist, a creator"

The specialized teacher, according to Medi, "plays a primordial role in the life of handicapped students". He must, with regards to this important position, deepen his knowledge in the field of "handicap": "The teacher is supposed to know ${ }^{4}$, he must be open to other subject-matters and other specialties get access to knowledge, he must perform several roles such as the role of raising a family and the role of educator". This double role focuses on the teaching practice which, according to Medi, must be based on creativity, reflection, commitment and devotion to the job: "the teacher must somewhere be a creator". He also points out that "the teacher must have pedagogical, psychological competences together with outstanding human qualities". Medi wants to give a particular meaning to the Adapted Teaching Practice. What Bourdieu (1980) calls the "practical sense" (Rouzel, 2004: p. 14), on the other hand, thinks that the specialized teacher is the "handyman and the wizard of our society. Unlike the engineer, he does not dispose of a ready-made scheme, but he identifies the good opportunities and collects the elements in unexpected combinations on the basis of what he finds".

3) "Team work enlightens our path"

The work in collaboration with a team of the pre-disciplinary follow-up "enlightens our path” declares Medi. For him, "working alone is almost impossible"; the teacher cannot control everything. There are things which escape from his control and which the psychologist for instance or any member of the follow up team can have a rapport. This "collective synergy" is important to well-schedule and mainly to evaluate and have finally a positive result which links together the medical, paramedical and educative aspects. Indeed, according to Medi, "teamwork is a sort of guide after collective reflection on the needs, the problems and the solutions to be brought in order to overcome the experienced difficulties". In the same framework, Freud spoke of a mind exercise in the educative job which requires un "après-coup" effect and which is achieved through a permanent come-and-go between the act and the thought" (Freud, 1985).

\subsection{The Intentional 'Déjà-Là'}

The notion of intention is central and indispensable in the field of didactic research (Portugais, 1999). According to Medi, intention means the concentration on the handicapped student and it's from the latter's characteristics that didactic intentions are built. Besides, Medi considers his student as a reference for programming sessions and outline his objectives from the beginning. Ha says: "As for me, I always and primarily refer to my handicapped student, his needs, his difficulties, then comes the manner and the means to achieve this objective through physical activities". Therefore, for him, the intention springs from the field. Indeed, it relies on the fact that having deep knowledge on the handicap remains always very theoretical. The Know-How is all that is important for him: "to have knowledge is very important to conceive a well-thought work which responds to the needs of my" handicapped' students (between brackets), one must apply to a more reflected real and practical context on field".

This echoes Rouzel's words (Rouzel, 2004: p. 4) on the fact that 'being close to the action and the reflection without letting loose either one”.

Besides, and for the purpose of detecting more subtly Medi's intentions, we have asked him on the objectives which he might anticipate during the gymnastics sessions ${ }^{5}$. We have noticed that his replies always refer to the handicap which has become the centre around which gravitate all his pedagogical intentions. He states: "Well, in gymnastics, it is a bit complicated for me, but I believe that my objectives will have as a starting point the evaluation of difficulties that my students may encounter in relation to the gymnastics activity. I cite for instance

\footnotetext{
${ }^{4}$ In clinical didactics, the teacher embodies symbolically, in the institution and in the classroom, the position of the one who knows. The "subject supposed to be known" is a conceptual tool for the analysis in a particular manner that each teacher occupies the function of detaining and transmitting knowledge (Carnus \& Terrisse, 2013).

${ }^{5}$ Gymnastics represents the supporting activity in our study.
} 
memorization, coordination and logical sequence of two or more elements, but it is certain that I will never insist on accuracy and efficiency of movements and gymnastics elements". This speech allows us to notice that the motor activity as such does not seem to be its first worry, what are most important lies in concentrating on the student who must not fail by proposing to him situations that are suitable for him. Already, he states in this context: "For me, my student must succeed, must move, must feel his body in space and must improve....and his performance means the progress that he will reach compared to his level in the beginning”. Thus, we can say that the rapport of Medi towards the handicap seems to influence some objects designed as knowledge to be taught (Portugais, 1999). According to Carnus (2009: p. 64), "The intention depends more on the institution than on the subjects. This social intention of teaching an instituted knowledge is transformed by the teacher into private intentions compared with this same knowledge. This mutation is operated from what he knows and what he is and in particular in the didactic intentions".

Thus, Medi who, from his "déjà-là" made of conceptions, intentions and experience, seems to find his professional balance nursed by a strong personal implication of affects, desire and pleasure. This personal implication is in fact a strategy based on the rational that Medi has chosen to impose himself in the contingent and uncertain context of teaching physical activities to handicapped student.

\section{The Case of Manel}

\subsection{Experiential Déjà-Là}

Manel is an APA teacher at the Institute of Promotion of the Handicapped (IPH) in Tunisia. She has ten years of experience. She states that her choice to follow the course of formation was an "adventure" in which she wanted to get involved with the support of her mother who works in the Ministry of Social Affairs and who had an idea on the pertinence and the importance of working in specialized institutions with students who have particular needs. Manel justifies her choice by the fact that this option of training at the Higher Institute of Sports and Physical Education was also a new option: "Why not, I would like to be among the first who provide teaching to the handicapped, which remains, however, something that is not always evident" she told us. We understand that Manel launches herself into an adventure as she says and seems to impose herself in the context of handicap since she adds: "By nature, I love going beyond the 'normal', I am fond of making the exception".

1) The missing academic formation

For Manel, the formation that she received is incomplete and it is oriented essentially towards the performance handy-sport. For her, one must not mix up sport performance and teaching as "there is a big difference between adapted sort and adapted physical activity, it is like the difference between Physical Education and sport".

The formation she has received does not cover all types of handicap. She has been directed mainly on the handicap motor and she justifies this by the lack of specialists for specialized teaching. Besides, she states that by getting to the field which for her represents "a very realistic mine of information and far from the idealistic theories that one can learn during his education whether at university or after university", she did not need to use the strategies or notions acquired at ISSEP. Manel, our "daily adventurer" (Gomez, 2004: p. 80), thinks that it is a context where the teacher does not stop creating: "We are here to adapt and adapt ourselves".

2) Manel between society rejection and adoption of the handicapped

After ten years of professional experience in the handicap environment, Manel says that "one must change his attitude towards the handicapped. One must be more flexible, patient, more understanding, one must feel their needs. One must adopt them in the true meaning of the word." For her, her mission consists in mitigating society's rejection of the handicapped person. Indeed, she tells us: "already, they are rejected by society. So, in my opinion, my role is to love them, give them our hearts, everything whatever, for they must be persons who share our life". At this level of the analysis, we ask ourselves whether this mode of the handicapped person's adoption claimed by Amel could have any relation with her mother who works in the Ministry of Social Affairs and who pushed her to choose this branch of studies. Did she also transmit to her daughter the desire to "fill in" or "repair" this social phenomenon of the handicapped person and its representation in society?

\subsection{Conceptual Déjà-Là}

In his conception of the handicap, Manel keeps exposing the social aspect by saying that the handicap "remains however a social phenomenon, we cannot deny that, otherwise all these institutions and these specialized cen- 
ters wouldn't have existed". But, rapidly she puts herself in the position of the specialized teacher with another representation of the handicapped person who, according to her experience becomes a limited person but also someone who is able to integrate into society and who can be autonomous. To better express herself, Manel uses an example: "You certainly know about the most difficult and the most delicate handicap which is Trisomy 21 disability (Down's syndrome). Well, we had in our centre a case of Trisomy 21 (Down's Syndrome) 21 and this handicapped person, after spending some time at the centre managed to work at his father's office as a cashier and I have witnessed this with my own eyes and was positively surprised; it is a good example among many other ones".

1) A teaching "framed" in a familial and convivial relationship

Manel insists, in her speech, on the important role that must be played by the teacher towards the students with special needs. She declares that, at this level, the "teacher must accomplish the role of the family, the mother's tenderness and affection, the father's encouragement, the support, the pleasure and the commitment so as to see their son move up, integrate, laugh, participate in doing something, etc.". She adds that the teacher must with the required pedagogical competences. She talks about the evaluation, the choice of adequate and well-thought of objectives, making decisions in the right time and opting for pertinent teaching strategies combined with a pedagogy of success since the handicapped person needs always to be valorized, to be successful. Failure, on the contrary, does not allow him to move up; therefore the teacher must manage all this. You understand that it is not evident at all.

The teacher speaks of her function and the competences that a specialized teacher must acquire, but her declaration seems to us under a desire on non-confessed, non-acknowledged or even denied influence. We could not withdraw from her speech concepts related to APA teaching and the requirements of this type of teaching based in particular on know-how and on very specific strategies. "I teach as I imagine teaching should be, not as they taught me to do. Besides, I no longer know exactly what I learnt pedagogically. You can be given ideas, recipes, but believe me, they cannot be used, it is a little bit blurred, and I don't know if pedagogy is learnt. In any case, as for me, I rely so much on my instinct." For Manel, it seems then that the competences of a specialized teacher are a kind of "mirage" to make believe of the existence of a strategic norm allowing to transmit a corporal savoir faire through physical activities as the reality of the field quickly shows the limits of any strategy. On the contrary, we notice a very strong personal and affective involvement of the teacher, and this might limit the real function of a teacher of physical activities in a specialized institution: "here, I do everything with my students, it's as though they were my own kids, we eat together, we organize outings, sometimes we stop the PE session and do another activity. Therefore, we can't follow a ready-made strategy or method of work. And even sometimes I have the feeling that I am doing accompaniment. What matters most is, security and the beaming faces of my students".

2) Teamwork: a factor of professional and intellectual stimulation

Manel thinks that the organization and the dynamism of the multi-disciplinary team in the centre is a factor of professional stimulation based on solidarity and openness to new ideas and to dialogue. Indeed, she considers that "teamwork is important, collaborate in order to emit objectives and work axes together helps a lot and this allows us to get a clear and well-thought vision of our work in general".

On the other hand, she suggests completing this collaborative work by a regular presence and each in turn for psychologists, ergo-therapists and all the other members of the team on field. In this context, she adds: "this could mean more than having theoretical and verbal evaluation without any follow up."

\subsection{Intentional "Déjà-Là"}

Manel is torn between her position as a teacher and her duty as a specialized teacher. Access to Manel's intentions seems a bit difficult because for her, having intentions and objectives before moving to the field remains somehow uncertain and unstable. On the contrary, she estimates that it is rather the intentions which change with the framework, the situation and the state of the student himself. This teacher seems to find difficulties to position herself as a teacher in her relationship with a mentally-handicapped student. She says: "certainly there is a basis for my work, after all I am going to transmit knowledge for handicapped students; Therefore, I pay attention to security, I insist on games, I try to create achievable motivating situations, I am close to my students, I give them the opportunity to let off steam, I put them in a state of self-confidence, etc... but one cannot deny that it is almost impossible to get everything ready in advance. Anyway, this is my opinion”. This sends us back 
to what Blanchard-Laville (2001: p. 75) calls "the teacher's print" which is defined as "a scenario laid by the teacher in a psychic space of the classroom and which is linked to the knowledge he expresses in the situation". For Manel, this particular and uncommon touch reveals her personal reference to assume her daily work. She points out that her references are "her heart, her intuition and her brain, and that's all in all". We feel indeed this conflict which can be translated into suffering or into tension between her symbolic function as a teacher and her real and effective function on field.

Manel illustrates her words by another example: "yesterday, I came as usual with the intention of playing games of reaction and speed of reaction. But there was a problem. One of the girls refused to work. She was on the brink of depression, she was crying, and she lacked motivation. I got nearer to her and asked her this question: "what would you like to do today? She replied: 'I want to dance'. And, consequently, I turned my session of speed of reaction into a dancing session and I participated myself in this activity." According to Manel, the specialized teacher is not thoroughly free and she does not have full control of his didactic and pedagogical choices. She is submitted to external and internal constraints which make his professional practice difficult and complex. This leads us to Freud's saying (Freud, 1927) according to which "the 'ego' is not master in his own home". Besides, for the same author, the job of teaching is an "impossible" job.

Thus, we perceive tensions at the heart of Manel's "intentional déjà-là" between her symbolic function as a subject supposed to know and the real side of her activity as a teacher of adapted physical activities (APA) which are characterized - among other things - by a necessary adaptation to the contingency and the unexpectedness of events.

\section{Conclusion}

Our intention in this article was to focus on the "decisional déjà-là" of two specialized teachers, which sent back to a latent and influential part of the history of subjects, acting as a "filter of the didactic action" (Loizon, 2004) This decisional déjà-là is a mixture of experiential, conceptual and intentional déjà-là which reveals the complexity and the multiplicity of possible internal influences at the moment of decision-making (Carnus, 2002).

By looking at the obtained results and starting from the two presented clinical didactic vignettes, we have been able somehow to make certain conscious and unconscious psychic dynamics appearing into action, which determines the practices of the specialized teachers. These dynamics focus in particular on the psychic positions of the professionals, their rapports to knowledge and towards the handicap and their expression in the institutional contexts of exercise.

It seems, according to the results obtained with these teachers at this stage of the research, that the specialized educative relation emphasizes an animated teaching motivated by a strategy based greatly on the assessment and the maintaining of a favorable affective relationship. This strategy, partly unconscious (Robert \& Carnus, 2013) requires at the same time a process of identification and a benevolent attitude. According to Klein (1978), "the capacity of identifying oneself to the other is a condition for loving really". We can spot this strategy through the intimate relationship between Medi and his student with particular needs, thus the teacher exposes himself to the other and becomes more sensitive to the counter-transfer ${ }^{6}$ (Vandermersk \& Chemama, 2009: p. 112). Aulagnier (1975) evokes also the "narcissi contract" which represents the formation of an unconscious link binding the specialized teacher to his particular student. From Medi's speech, we dare give this kind of interpretation. Besides, this teacher uses expressions such as "love", "pleasure" and he focalizes rather on the handicapped person himself than on the teaching methods and strategies. For him, in his relationship with his students, it is the subject which is exposed, not the knowledge.

On the other hand, Manel has a broader vision of the handicap and she always refers to the societal reference and to the needs of the handicapped person. She is doing this job without hiding her conflict between her symbolic function as a teacher and her real function as a specialized teacher. Triggered by the desire to satisfy her students and release them from social rejection, Manel thinks that the education relationship is a relationship which remains ambiguous and hard to schedule in view of an uncertain framework in which she performs her duty.

In both cases, it seems then that the focalization on the rational, the exchange, the sharing, the identification

\footnotetext{
${ }^{6}$ Freud talks in his works about the transfer and the counter-transfer of conscious and unconscious affective reactions of the analyst towards the analyzed person. For him, the counter-transfer is defined in negative terms because the counter-transfer might interfere to disturb the analyst's treatment: "during a treatment, no analyst can go beyond what his own complexes and internal resistances allow him to go" (Freud in Vandermerc, Chemama, opt. cit).
} 
and the empathy direct the teaching practices as if teachers are exercised a "hollow" job so that the other (here the handicapped student) feels allowed to lay all his hopes, his ambitions, his needs and his desires. At the same time, the interrogated teachers find a real difficulty and even a frustration to situate themselves as a teacher in their educative relationship with the handicapped students.

We could add that from the obtained results, we were able to follow the development and the personal and particular itinerary that each of the two cases Medi and Manel were able to follow in order to build up what Jourdan (2006) called "professional logic". This also echoes a "professional ego" identified by Aulagnier (1975: p. 194) as a concept "made of a story, represented by a set of identifying statements of which he keeps the remembrance, by the statements which appear in his present life through his relationship with the identifying project”.

This makes up a provisional conclusion in consideration to the advances in our work of thesis. At the end of this exploratory stage, the project consists in observing in situ these two teachers during the test which represents the second time of the clinical didactic methodology (clinical interaction time). In a third and last time, the "après-coup" which will trigger a return on the professional practices and will give an account on the process of "restructuration" and reconstruction of memory sources of experiences and achieve our analyses. This three-time methodology, (déjà-là, test and après coup), shall allow us to cast a new look on the specialized teaching practices in the field of adapted physical activities (APA).

\section{References}

Aulagnier, P. (1975). The Violence of Interpretation. From Pictogram to Statement. Paris: PUF. http://dx.doi.org/10.4324/9780203361290

Bardin, L. (1977). The Content Analysis. Paris: PUF.

Beillerot, J., Blanchard-Laville, C., \& Mosconi, N. (1996). Towards a Clinic of "Rapport au Savoir" (Relationship to Knowledge). Paris: L’Harmattan.

Brunet, F., Bui-Xuan, G., \& Bluteau, S. (2001). Teaching and Animating the Adapted Physical Activities for People with Intellectual Disabilities. In J. Bilard, G. Ninot, \& A. Varray, (Dir), Teaching Adapted Physical Activities (pp. 134-142). Revue EPS, No. 55.

Blanchard-Laville, C. (2001). Teachers between Pleasure and Suffering. Paris: PUF.

Bourdieu, P. (1980). The Practical Sense. Paris: Editions de Minuit.

Bru, M. (1992). The Didactic Variations in the Organization of learning Conditions. Toulouse: South University Editions.

Carnus, M. F. (2002). Beliefs, Conceptions, Intentions and Effective Practices in the Teaching of Gymnastics. In J. F. Robin, \& A. Durny, (Eds.), Current Work in Gymnastics and Acrobatic Activities (pp. 160-164). Dossier EPS, 57, Paris. Paris: Editions Revue EPS.

Carnus, M. F. (2003). Didactic Analysis of the Decision-Making Process of Teachers in Physical and Sports Education. A Study of Crossed Cases. In C. Amade-Escot, (Ed.), Didactic of Physical Education, State of Research (pp. 193-224). Paris: Editions EPS.

Carnus, M. F. (2009). The Teacher's Decision in Clinical Didactic. A Case Study in Physical Education. In A. Terrisse, \& M. F. Carnus, (Dir), Clinical Didactic of Physical and Sports Education, Which Issues of Knowledge (pp. 63-81)? Bruxelles: De Boeck.

Carnus, M. F. (2013). Teacher Is Not Master in His/Her Own Institution. In M. F. Carnus, \& A. Terrisse, (Ed.), Clinical Didactic of Physical and Sports Education, Teachers Entity in Question (pp. 23-32). Paris: Revue EPS.

Carnus, M. F., \& Terrisse, A. (2013). Clinical Didactic of Physical and Sports Education, Teacher's Entity in Question. Paris: Revue EPS.

Ciccone, A. (2012). The Unconscious Psychic Transmission, Projective Identification and Phantasm of Transmission. Paris: Dunod.

Freud, S. (1927). The Future of an Illusion. Paris: PUF.

Freud, S. (1985). Construction in the Analysis. In Results, Ideas, Problems (pp. 269-283). Paris: PUF.

Gomez, J. F. (2004). An Educator in Walls. Anti-Pedagogical Poem for the XXI Century. Paris: Téraèdre.

Haber, S. (2012). Freud and Social Theory. Paris: La Dispute.

Jourdan, I. (2006). Relation to the Body, Relation to Sports and Artistic Physical Activities and Professional Logic: Two Case Studies in Initial Training in Physical and Sports Education. Aster, 42, 57-78. 
Klein, M., \& Riviere, J. (1978). Love and Hatred. Paris: Payot.

Loizon, D. (2004). The Clinical Analysis of the Experience of Teachers and Knowledge Transmission: Clinical Research in Educational Sciences, Contribution for an Analysis of Teaching Practices, 5th Congress of l'AECSE. Paris: CNAM.

Mucchielli, R. (1975). Content Analysis. Paris: ESF.

Robert, M., \& Carnus, M. F. (2013). Nonverbal Ostensive Forms in Gymnastics, Constitutive of Professional Signature of Two PE Teachers. In M. F. Carnus, \& A. Terrisse, (Dir). Clinical Didactic of Physical and Sports Education. Teachers Entity “le sujet enseignant” in Question (pp. 81-92). Revue EPS (Eds.).

Rouzel, J. (2004). The Daily Practices in Special Education. Paris: Dunod.

Terrisse, A., \& Carnus, M. F. (2009). Clinical Didactic of Physical and Sports Education: What Stakes of Knowledge? Bruxelles: De Boeck University.

Vandermersch, B., \& Chemema, R. (2009). Dictionary of Psychoanalysis. Paris. 